\title{
MHD Rivlin-Ericksen Free Convective Memory Flow through Porous Medium
}

\author{
Rafiuddin \\ Department of H\&S, CVR College of Engineering, Hyderabad, India \\ Email: rafiuddin2008@gmail.com
}

\begin{abstract}
Effects of free convective two dimensional unsteady Rivlin-Ericksen memory flow through porous medium of variable permeability, bounded by vertical porous plate with uniform suction and constant heat flux under the influence of uniform transverse magnetic field are studied. The permeability of porous medium fluctuates with time about a constant mean. Approximate solutions are found for mean velocity, transient velocity and temperature distribution. The temperature distribution and mean velocity are shown graphically and discussed.
\end{abstract}

Index Terms - Magneto hydrodynamics, Free convection, Rivlin-Ericksen memory fluid, Porous medium.

\section{INTRODUCTION}

In recent years, the problem of free convection flow through a porous medium of variable permeability has attracted the attention of many scholars. Sreekanth et al. [3] studied the fluctuating free convection through porous medium due to an infinite vertical plate with variable permeability. Rees and Pop [5] investigated free convective flow in porous medium of variable permeability effects. Singh et al. [6] have studied MHD free convective viscous flow past the vertical porous plate through nonhomogenous porous media with radiation and temperature gradient dependent heat source in slip flow regime. Batarseh and Duwawri [7] have studied Isentropic sound propagation analysis and optimization over flat plate of saturated porous media of variable permeability. Noushima et al. [8] have studied Hydro Magnetic free convective Rivlin - Erickson flow through a porous medium of variable permeability. Uwanta et al. [9] analysed the heat and mass transfer flow through porous medium of variable permeability. Babu and Satya[10] have studied the influence of variable permeability and radiation absorption on heat and mass transfer in MHD micro-polar flow over a vertical moving porous plate. The variable permeability problem bounded by vertical plate has possible application in design of steam displacement process in oil recovery and geothermal systems.

Aim of the author is to extend the problem of [4] to Rivlin-Ericksen fluid [1] under the influence of transverse magnetic field.

\section{FUNDAMENTAL EQUATIONS}

The convective memory flow through a porous medium bounded by an infinite vertical porous plate with constant heat flux subject to uniform transverse magnetic field is considered. $\mathrm{x}$ - axis is taken along the plate in the upward direction and $\mathrm{y}$-axis normal to it .

All the fluid properties are assumed to be constant, except the influence of density variations with temperature is considered only in the body force term. The magnetic field of small intensity $\mathrm{H}_{0}$ is induced in the ' $\mathrm{y}$ 'direction since the fluid is slightly conducting, the magnetic Reynolds number is very much less than unity hence the induced magnetic field is omitted in comparison with the applied magnetic field. The viscous dissipation and Darcy's dissipation terms are omitted for small velocities. The flow in the medium is entirely due to buoyancy force. Under these conditions, the governing equations of flow are

$$
\begin{gathered}
\frac{\partial v}{\partial y}=0 \quad \text { i.e } v=-v_{0} \\
\frac{\partial u}{\partial t}+v \frac{\partial u}{\partial y}=g \beta_{1}\left(\mathrm{~T}-\mathrm{T}_{\mathrm{z}}\right)+\theta \frac{\partial^{2} \mathrm{u}}{\partial \mathrm{y}^{2}} \\
+\frac{\beta}{\rho}\left[\frac{\partial^{2} \mathrm{u}}{\partial t \partial \mathrm{y}^{2}}+v \frac{\partial^{2} \mathrm{u}}{\partial \mathrm{y}^{2}}\right]-\frac{\partial \mathrm{u}}{\mathrm{k}(\mathrm{t})} \\
-\left(\frac{\partial \mu_{\mathrm{E}}^{2} \mathrm{H}_{0}^{2}}{\rho}\right) \mathrm{u} \\
\frac{\partial \mathrm{T}}{\partial t}+v \frac{\partial \mathrm{T}}{\partial \mathrm{y}}=\frac{\mathrm{R}}{\rho \mathrm{C}_{\mathrm{p}}} \frac{\partial^{2} \mathrm{~T}}{\partial \mathrm{y}^{2}}
\end{gathered}
$$

Where $\mathrm{u}$ and $\mathrm{v}$ are velocity components along $\mathrm{x}$ and $y$ axes, and ' $\mathrm{k}$ ' is the permeability of porous medium.

$$
k(t)=k_{0}\left(1+a e^{i n t}\right)
$$

Where ${ }^{\prime} k_{0}$ is the mean permeability of the medium, 'w' the frequency of fluctuation, 't ' the time and ${ }^{\prime}(<<1)$ is a constant quantity.

The boundary conditions are:

$$
y=0, \quad u=0, \quad \frac{\partial T}{\partial y}=-\frac{q}{K}
$$




$$
\mathrm{y} \rightarrow \infty, \quad \mathrm{u}=0, \quad \mathbf{T}=\mathbf{T}_{\mathrm{c}}
$$

Introducing the following non-dimensional quantities:

$$
\begin{aligned}
& y^{\prime}=\frac{y v_{0}}{\theta}, t^{\prime}=\frac{t_{0}^{2}}{4 \theta}, \quad \omega^{\prime}=\frac{4 A 0}{v_{0}^{2}}, \\
& \mathrm{M}=\frac{\mathrm{\sigma OH}_{0}^{2} \mu_{\mathrm{e}}^{2}}{\mathrm{Pv}_{0}^{2}}, \quad u^{r}=\frac{\mathrm{u}}{\mathrm{v}_{0}}, \quad \mathrm{P}=\frac{\mu \mathrm{C}_{\mathrm{p}}}{\mathrm{K}} \\
& \mathbf{G}=\frac{g p_{1} q^{2}}{\kappa v_{0}^{4}}, \quad k_{0}^{3}=\frac{k_{0} v_{0}^{2}}{\theta^{2}}, \quad R=\frac{\rho_{1} v_{0}^{2}}{\theta^{2}}, \\
& \theta=\frac{\left(\mathrm{T}-\mathrm{T}_{\mathrm{z}}\right) \kappa v_{0}}{\mathrm{q}}
\end{aligned}
$$

The equations (2.2) and (2.3), in view of (2.4) and (2.6) reduce to the following form.

$$
\begin{aligned}
\frac{1 \partial u}{4 \partial t}-\frac{\partial u}{\partial y}=c \theta+\frac{\partial^{2} u}{\partial y^{2}}+R\left(\frac{\partial^{2} u}{4 \partial t \partial y^{2}}-\frac{\partial^{2} u}{\partial y^{2}}\right) \\
-\frac{u}{k_{0}\left(1+a e^{i \theta t}\right)}-M u \\
\frac{1 \partial \theta}{4 \partial t}-\frac{\partial \theta}{\partial y}=\frac{1}{P}\left(\frac{\partial^{2} \theta}{\partial y^{2}}\right)
\end{aligned}
$$

The corresponding boundary conditions become

$$
\begin{array}{r}
y=0, \quad u=0, \quad \frac{\partial \theta}{\partial y}=-1 \\
y \rightarrow \infty, \quad u=0, \quad \theta=0
\end{array}
$$

\section{SOLUTION OF THE PROBLEM}

The partial differential equations (2.7) and (2.8) are reduced to ordinary ones by assuming the following series expressions for velocity and temperature fields.

$$
\begin{aligned}
& u(y, t)=u_{0}(y)+z e^{j \omega t} u_{1}(y) \\
& \theta(y, t)=\theta_{0}(y)+\varepsilon e^{i v t} \theta_{1}(y)
\end{aligned}
$$

Substituting equations (3.1) and (3.2) in equations (2.7) and (2.8) and equating the coefficients of like powers of $\varepsilon$ to zero, the differential equations so obtained are

$$
\begin{aligned}
& \mathrm{Ru}_{0}-\mathrm{u}_{0}^{u}-\mathrm{u}_{0}^{\prime}+\left(\frac{1}{\mathrm{k}_{0}}+\mathrm{M}\right) \mathrm{u}_{0}=\mathrm{G} \theta_{0} \\
& R u_{1}-\left(1+\frac{R i \omega}{4}\right) u_{1}^{u}-u_{1}^{\prime}+\left(\frac{1}{k_{0}}+M+\frac{i \omega}{4}\right) u_{1}
\end{aligned}
$$

$$
=\mathrm{G} \theta_{1}+\frac{\mathrm{u}_{0}}{\mathrm{k}_{0}}
$$

$$
\begin{gathered}
\left(\frac{1}{\mathrm{P}}\right) \theta_{0}^{\prime}+\theta_{0}^{\prime}=0 \\
\left(\frac{1}{\mathrm{p}}\right) \theta_{1}+\theta_{1}^{\prime}-\left(\frac{10}{4}\right) \theta_{1}=0
\end{gathered}
$$

The corresponding boundary conditions become

$$
\begin{aligned}
& \theta_{0}^{\prime}=-1, \theta_{1}^{\prime}=u_{0}=u_{1}=0 \text { as } y=0 \\
& \theta_{0}=0 . \theta_{1}=0=u_{0}=u_{1}=0 \text { s.s } y \rightarrow \infty
\end{aligned}
$$

The differential equations (3.3) and (3.4) are of third order when $\mathrm{R} \neq 0$ and two boundary conditions are there. So Beard and Walters [2] rule gives rise to,

$$
\begin{array}{r}
u_{0}=u_{01}+R u_{02}+o\left(R^{2}\right) \\
u_{1}=u_{11}+R u_{12}+o\left(R^{2}\right)
\end{array}
$$

Substituting these equations (3.8) and (3.9) into (3.3) and (3.4) equating different powers of $\mathrm{R}$ and neglecting, $\mathrm{o}\left(\mathbf{R}^{2}\right)$, there by

$$
\begin{gathered}
u_{01}^{\prime \prime}+u_{01}^{\prime}-\left(\frac{1}{k_{0}}+M\right) u_{01}=-G \theta_{0} \\
u_{11}^{\prime \prime}+u_{11}^{\prime}-\left(\frac{1}{k_{0}}+M+\frac{100}{4}\right) u_{11}=G \theta_{1}-\frac{u_{01}}{k_{0}} \\
u_{02}^{\prime \prime}+u_{02}^{\prime}\left(\frac{1}{k_{0}}+M\right) u_{02}=u_{01}^{w} \\
u_{12}^{\prime \prime}+u_{12}^{\prime}+\left(\frac{1}{k_{0}}+M\right) u_{12}=u_{11}^{w}-\left(\frac{100}{4}\right) u_{11}^{w}-\frac{u_{02}}{k_{0}}
\end{gathered}
$$

The boundary conditions are

$$
\begin{aligned}
u_{01}=u_{02} & =u_{11}=u_{12}=0 \text { as } y \rightarrow 0 \\
u_{01} & =u_{02}=u_{11}=u_{12}=0.3 \mathrm{y} \rightarrow \infty
\end{aligned}
$$

The velocity and temperature fields are given by

$$
\begin{gathered}
u=u_{0}+z u_{1} \\
u=u_{01}+R u_{02}+\varepsilon\left(u_{11}+R u_{12}\right) \\
=u_{01}+R u_{02}+\varepsilon u_{11} \\
e=\theta_{0}+z \theta_{1}
\end{gathered}
$$


Solving (3.10 - 3.13) under boundary conditions (3.14), taking real part of the solution and can be put into form of fluctuating parts

$$
u(y, t)=u_{0}(y)+\varepsilon\left[M_{\mathrm{r}} \cos \omega t-M_{\mathrm{i}} \sin \omega t\right]
$$

The expression of transient velocity profiles for $\omega t=\pi / 2$ is given by

$$
u(y, \pi / 2 \omega)=u_{0}(y)-\varepsilon M
$$

Where

$$
\begin{aligned}
& u_{n}(y)=\frac{G}{P_{2}}\left[\left(e^{-r_{1} y}-e^{-P_{r} y}\right)\left(1-R P_{n}\right)-R r_{2} e^{-r_{1} y}\right] \\
& \theta(\mathrm{y}, \mathrm{t})=\left(\frac{1}{\mathrm{p}}\right) \mathrm{e}^{-\mathrm{P} y}
\end{aligned}
$$

For the sake of brevity constants and fluctuating parts are not given.

\section{CONCLUSIONS}

The temperature distribution decreases as Prandle number increases, is shown in fig 1 . The mean velocity profiles are plotted in fig 2 . Mean velocity increases with Grashoff number ' $\mathrm{G}_{\mathrm{r}}$ ' and Permeability parameter ' $\mathrm{k}_{0}$ ' but decreases with Prandle number $\mathrm{P}_{\mathrm{r}}$ and Hartmann number 'M'.

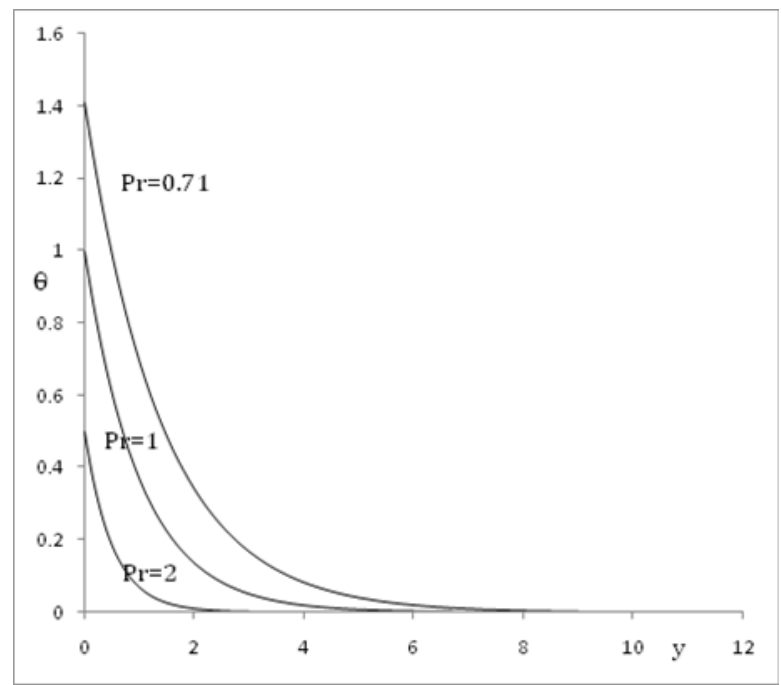

Figure 1. The temperature profiles for different values of Prandle number

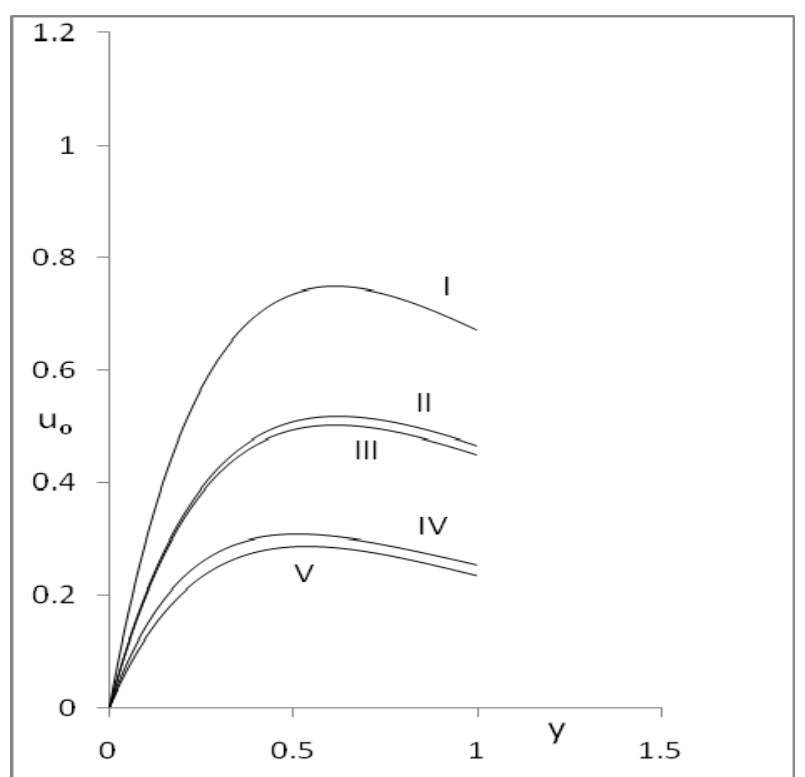

Figure . 2. Effects of $k_{0}, M, G_{r} P_{r}$ on mean velocity $u_{o}$ versus y for $R=$ 0.05

\begin{tabular}{|c|c|c|c|c|}
\hline & $\mathrm{P}_{\mathrm{r}}$ & $\mathrm{M}$ & $\mathrm{G}_{\mathrm{r}}$ & $\mathrm{k}_{0}$ \\
\hline $\mathrm{I}$ & 0.71 & 5 & 6 & 3 \\
\hline $\mathrm{II}$ & 0.71 & 5 & 4 & 10 \\
\hline $\mathrm{III}$ & 0.71 & 5 & 4 & 3 \\
\hline $\mathrm{IV}$ & 0.71 & 10 & 4 & 3 \\
\hline $\mathrm{V}$ & 1 & 5 & 4 & 3 \\
\hline
\end{tabular}

\section{REFERENCES}

[1] R.S. Rivlin and J.L. Ericksen "Stress deformation relation for isotropic materials",Jour. Rat Mech. Vol.4, (1955) 323.

[2] D.W. Beard and K. Walters: "Elastico-viscous boundary-layer flows. I. Two-dimensional flow near a stagnation point", Proc. Camb. Phil. Soc. 60, (1964) 667-674.

[3] S. Sreekanth, S. Venkataramana and S. Ramakrishna "Hydrodynamic free convective flow through a porous medium with variable permeability", Acta Ciencia Indica,Vol XXII M ( 3 ), (1996) 267.

[4] A. Mesharshi and S.S. Tak " Fluctuating free convection through porous medium due to infinite vertical plate with constant heat flux", J. Indian Acad Math ,vol .22, (2000) 293.

[5] D.A.S. Rees and I..Pop "The vertical free convection in porous medium with variable permeability effects", International Journal of Heat and Mass transfer Vol 43 (2000) 2565-71

[6] N.P. Singh, A. Kumar, A.K. Singh and A.K. Singh "MHD free convection flow of viscous fluid past vertical porous plate through non-homogenous porous media with radiation and temperature gradient dependent heat source in slip flow regime", Ultra Sci. Phys. Sci. India 18, (2006) 39-46 .

[7] L.R. Batarseh, H.M. Duwawri "Isentropic sound propagation analysis and optimization over flat plate of saturated porous media with variable permeability", Vol 18(1m) (2006) 55-62 
[8] G.H.Noushima, M. V. Ramana Murthy, M. C. K. Reddy, Rafiuddin, A. Ramu, and S. Rajender "Hydro Magnetic free convective Rivlin - Erickson flow through a porous medium with variable permeability", International Journal of Comp. and Applied Mathematics, 5(3), (2010) 267 - 275.

[9] I.J. Uwanta, M.M. Hamza and M.O. Ibrahim "Heat and mass transfer flow through porous medium with variable permeability and periodic suction" International journal of computer Applications Vol 36 (2) (2011) 6-11

[10] D.H. Babu and P.V. Satya Narayane "Influence of variable permeability and radiation absorption on heat and mass transfer in MHD Micro-polar flow over a vertical moving porous plate", Hendawi Pub. Corporation ISRN Thermodynamics International Scholarly Research Notices Volume (2013) 